\title{
INTERSECÇÕES ENTRE MEMÓRIA E FEMINISMO
}

\section{INTERSECTIONS BETWEEN MEMORY AND FEMINISM}

Anna Raquel de Lemos Viana ${ }^{1}$

Maria Nilza Barbosa Rosa ${ }^{2}$

(iD) Izabel de França Lima $^{3}$

${ }^{1}$ Mestranda em Ciência da Informação (PPGCI/UFPB),

E-mail: annaraquellemoss@gmail.com

2 Doutora em Letras pela UFPB, Pós-doutoranda em Ciência da Informação (PPGCI/UFPB)

E-mail: nilzasor@yahoo.com.br

${ }^{3}$ Doutora em Ciência da Informação pela UFMG, Professora do PPGCI e do PPGOA/UFPB

E-mail: belbib@gmail.com

\section{ACESSO ABERTO}

Copyright: Esta obra está licenciada com uma Licença Creative Commons Atribuição 4.0 Internacional. $(\mathrm{cc}) \mathrm{BY}$

Conflito de interesses: As autoras declaram que não há conflito de interesses.

Financiamento: Não há.

Declaração de Disponibilidade dos dados: Todos os dados relevantes estão disponíveis neste artigo.

Recebido em: 20/09/2019.

Revisado em: 01/10/2019.

Aceito em: 10/10/2019.

\section{Como citar este artigo:}

VIANA, Anna Raquel de Lemos; ROSA, Maria Nilza Barbosa; LIMA, Izabel de França. Intersecções entre memória e feminismo

Informação em Pauta, Fortaleza, v. 4, n.

especial, p. 31-46, nov. 2019. DOI:

https: //doi.org/10.32810/2525-

3468.ip.v4iEspecial.2019.42602.31-46.

\section{RESUMO}

Surgindo no contexto de ideais iluministas e transformadores da Revolução Francesa e Americana, posteriormente se espalhando no mundo todo, o feminismo, como movimento social, é essencialmente moderno e faz críticas à estrutura de poder patriarcal existente na sociedade através de discussões por direitos sociais e políticos. Atua em multiplicidade de relações, construindo articulações e se ampliando dentro do contexto mundial. Nessa perspectiva, esse artigo se propõe a percorrer a trajetória histórica por onde transitaram as dinâmicas políticas dos feminismos, refletindo sobre as intersecções da memória como fio condutor para o empoderamento, fortalecimento da identidade e a conquista dos direitos das mulheres.

Palavras-chave: Feminismo. Movimentos Sociais. Memória. Direitos. Política.

\section{ABSTRACT}

Arising in the context of "the age of enlightenment" and transforming ideals from the French/American Revolution and later spreading worldwide, feminism as a social movement is essentially modern and criticizes the existing patriarchal power structure in society, through discussions for social and political rights. It acts in a multiplicity of relationships, building articulations and expanding inboard the world context. Within this perspective, this article intends to go through the historical trajectory of the political dynamics of feminism, reflecting on the intersections of memory as a leader for women's empowerment, strengthening of identity and acquisition of women's rights.

Keywords: Feminism. Social Movements. Memory. Rights. Politics. 


\section{INTRODUÇÃO}

Questões de gênero sempre permearam acontecimentos históricos. Dentre elas, destaca-se o movimento feminista, que surge como crítica à modernidade, promovendo um questionamento político, cultural e moral. Além disso, apresenta, ao âmbito político, questões até então consideradas apenas de esfera privada, a saber: sexualidade, direito ao corpo, maternidade, aborto, violência contra a mulher, contracepção e maternidade. Aliadas a isso, as mulheres expõem assuntos do dia a dia e denunciam as desigualdades de uma cultura patriarcal, que valoriza a figura do homem em detrimento da mulher, e coloca em pauta o salário inferior comparado ao dos homens, a falta de divisão dos afazeres domésticos, a criação dos filhos, a participação política, entre outros aspectos.

Por meio de uma reflexão analítica, entende-se que o poder não é uma propriedade que pertence exclusivamente a um grupo ou uma classe (FOUCAULT, 1979), ou seja, não existem aqueles que detêm o poder (dominantes) e os que são dominados. Há uma rede, práticas de relações de poder. Sendo assim, o poder se constitui como algo que se exerce, se efetua, funcionando como estratégias, isto é, "formas díspares, heterogêneas, em constante transformação. 0 poder não é um objeto natural, uma coisa; é uma prática social e, como tal, constituída historicamente" (FOCAULT, 1979, p. 10).

Ainda segundo (FOCAULT, 1987), esse tipo de poder foi disseminado por todo o tecido social, ampliando-se e tornando- se "capilarizado". Ou seja, ao invés de o poder atuar de forma maciça e geral, acontece muitas vezes com mecanismos de poder, alicerçados por micropoderes, de forma sutil e distribuída. Vale ressaltar que os micropoderes não cessam os macropoderes, mas servem para sustentar ou multiplicar os efeitos deles. Percebe-se que as relações de poder ultrapassam o nível estatal e se estendem por toda a sociedade, evidenciando que, na modernidade, não é o Estado o centro de formação e controle de sociabilidade. Como complementa Agamben (2009), existem os dispositivos que se constituem como algo além das instituições (governo, escolas, manicômios), mas que têm a capacidade de capturar, orientar, determinar, assegurar os gestos e condutas, opiniões dos seres viventes, como a literatura, escritura, computadores. Sendo assim, considera-se tudo que exerce poder, de menor ou maior escala. 
Para melhor compreensão da estrutura do poder, Focault (1979) propõe analisar em suas extremidades, em suas formas e instituições mais regionais e locais, sobretudo indo além das regras de direito e que se organizam e delimitam, penetrando em intuições, virtualizando técnicas que passam a ser instrumentos de interação material, por vezes, violentos.

Tal perspectiva deve levar em consideração os movimentos sociais, que buscam, em ação coletiva, provocar mudanças sociais, dentro de um embate político, em um determinado contexto. Dentre eles, observa-se o movimento feminista como um movimento moderno, que surge a partir do contexto das ideias iluministas (1680-1780), com a Revolução Francesa (1789-1799) e Americana (1775-1781), reivindicando direitos sociais e políticos, com maior ênfase para a luta sufragista, através da mobilização de mulheres de vários países, afirma Oliveira (2014). Com características muito particulares, atentando-se para sua história e processos, "é um movimento que produz sua própria reflexão crítica, sua própria teoria” (PINTO, 2010, p. 12).

Ao dar visibilidade a reivindicações à esfera pública, o movimento feminista se mostra como interlocutor junto ao Estado, legitimando os direitos e denunciando a opressão cultural construída historicamente para silenciar as mulheres. Além disso, utiliza a memória coletiva como forma de construção social para fundamentar e reforçar os sentimentos de pertencimento e coesão dos grupos feministas.

Justifica-se a importância de reconstruir a história sobre as mulheres, a partir de lembranças, experiências e vivências dos movimentos feministas, e seu papel na organização e constituição de uma história que teve como protagonistas as mulheres. Estas deixaram suas marcas nas lutas cotidianas em suas várias dimensões e níveis, assim como em diferentes lugares e momentos históricos.

Le Goff (1990) aponta que a memória coletiva é posta como forma de luta pelas forças sociais de poder. Aqueles indivíduos que dominaram e desejam dominar as sociedades históricas se preocupam com a memória e o esquecimento das classes, grupos e indivíduos, como mecanismo de manipulação da memória coletiva.

Ademais, ao incorporar o direito à memória, o movimento feminista propõe reflexões sobre o discurso histórico, científico e político que privilegia o sujeito masculino, e promove a desconstrução dos modelos sociais tradicionais, em troca da construção da alteridade e inclusão das mulheres historicamente apagadas. 
Com a possibilidade de alterar e modificar fatos descritos a partir de novas percepções, os estudos sobre memória promovem mudanças sociais, pois permitem reconstruir o fenômeno, em função das preocupações éticas, pessoais, políticas e culturais de vários momentos vivenciados por diferentes sujeitos.

Neste artigo, busca-se discutir as bases em que se assentam os feminismos, levando em consideração o desconhecimento da sociedade acerca da história, evolução e articulação do feminismo, destacando participações de mulheres excluídas historicamente, bem como problematizando as práticas e discursos do uso da memória pelo movimento feminista, em suas constituições identitárias em busca de reconhecimento.

\section{MEMÓRIAS: REFLEXÃO DAS FEMINISTAS}

Do direito a estudar políticas públicas voltadas para a mulher, podem-se citar vários exemplos de conquista e institucionalização de pautas feministas, tanto no espaço público quanto no privado, que permitem o reconhecimento da capacidade feminina. No entanto, ainda há um desconhecimento da história do feminismo, em parte, pela limitação de bibliografia e reflexão teórica ao longo dos anos.

Para fins didáticos, o estudo sobre o feminismo divide-se em ondas feministas (the waves terminology), que, embora apresentem algumas controvérsias tanto no nível teórico quanto prático, elas são parâmetro cronológico e teórico. Uma "onda" feminista foi um momento histórico relevante de efervescência militante e/ou acadêmica em que determinadas pautas e questões das mulheres se insurgiram e dominaram o debate. (FRANCHINI, 2019).

Diferenciados por conjunturas, os feminismos são vistos, em geral, como irrupções em que, de repente, não mais que de repente, mulheres diversas se juntam, mostramse "irmanadas" na agitação de "causas" ou motivações políticas que se avolumam e que avançam como onda. Esta, depois de atingir um ponto alto, desce, invadindo os mais variados territórios, em diversos tempos; em seguida, tudo parece dissiparse. Diria que um maior rigor na produção do conhecimento dessas "causas" /motivações depende, sim, de pesquisa de fontes, mas sob uma leitura orientada por conceitos que admitam esses movimentos conjunturais como partes de um vasto tecido social, em grande medida, submersas, vindas de diferentes tempos históricos, trançadas entre si e que avançam em infinitas combinações de "ramificações", continuadas ou não, sinalizando movi mentos e transformações de visões de mundo (FRANCHINI, 2009, p. 4). 
Cada onda tem suas particularidades e facilita as formas de agrupar as mulheres de acordo com suas demandas e momentos históricos. "Assim, apesar de não haver um único posicionamento do movimento feminista, é possível identificar certos paradigmas ou ideologias predominantes que se revelam em reivindicações e pautas de determinada época". (SAFFIOTI, 1986, p. 105).

Entende-se que há, nas ondas feministas, uma síntese hegemônica de determinado período histórico demarcado por enfoques, estratégias e posições políticas. Dessa forma, são feitos recortes espaciais, temporais e teóricos dos movimentos feministas ao longo da história da organização de mulheres.

\subsection{Primeira Onda}

Inicialmente, nas últimas décadas do século XIX, na Inglaterra, as mulheres se juntaram para lutar por direito ao voto e ficaram popularmente conhecidas como sufragistas. A mulher, antes vista como ser do lar e feita para procriar, tem questionado a imposição dos papéis submissos destinados a elas. Portanto, como observa Pinto (2010), as primeiras reivindicações surgem com pedidos básicos, como direito ao voto e a participação política. Para isso, as mulheres promoveram grandes manifestações, e muitas, inclusive, foram presas ou fizeram greve de fome.

Já no Brasil, o feminismo surge posteriormente, também com a luta pelo direito ao voto. "As sufragistas brasileiras foram lideradas por Bertha Lutz, bióloga, cientista de importância, que estudou no exterior e voltou para o Brasil na década de 1910, iniciando a luta pelo voto" (PINTO, 2010, p. 16). Elas defendem que homens e mulheres são iguais em relação à capacidade moral e intelectual, e, portanto deveriam ter as mesmas oportunidades para trabalhar, estudar e participar da esfera pública, predominando, nesse período de militância, a defesa da igualdade.

Segundo Saffioti (1986, p. 107), a proposta fundamental era "ampliar o que se entende por democracia, tornando iguais perante a lei os crescentes contingentes humanos das sociedades competitivas. Nesta concepção, cabe reivindicar para as mulheres igualdade de direitos com relação aos homens no plano de jure".

Porém, a crítica a esse período consiste em afirmar que as pautas estavam ligadas a interesse de mulheres brancas e de classe média, e, por isso, eram pautas generalizadas de inclusão formal, não adentrando profundamente a estrutura patriarcal 
e machista construída. Mesmo que tenha se restringindo a conquistas "formais", é inegável o impacto causado na estrutura de poder patriarcal, por se constituir de um movimento massivo, em que a coletividade de mulheres ocupou espaços públicos (ruas, praças), causou tensões e consequentemente mudanças.

Marcam-se também as ideologias nazistas e fascistas deste período que culminavam num maior controle feminino e na tentativa de reforçar os papeis sociais como inerentes e naturais, marcando o arrefecimento das mobilizações populares como um todo (ALVES; PITANGUY, 1985, p. 49-50).

Ainda segundo (ALVES; PITANGUY, 1985, p. 50), “o papel estatal e midiático teve fundamental influência no retorno da mulher ao espaço doméstico e domesticado. As propagandas neste período exaltam a figura dona-de-casa servil ao marido, do papel de esposa e mãe e do fomento à indústria de beleza e estética."

Nesta reflexão, percebe-se a estrutura patriarcal predominante, e a forma como as mulheres lutaram para ter direitos e garantias em uma sociedade com cultura predominantemente masculina e machista. Ao fazer uma crítica cultural e questionar valores tradicionais, o feminismo entende que a cultura é dinâmica e pode sofrer alterações devido a eventos históricos, ou conflituoso contrato cultural, pois a cultura condiciona a visão do mundo do homem (LARAIA, 2001).

Construindo articulações e ampliando para um contexto mundial, como corroboram Bandeira e Melo (2010, p. 8), "o movimento feminista nasceu das lutas coletivas das mulheres contra o sexismo, contra as condições de aversão e inferiorização feminino, transformadas em práticas rotineiras de subordinação".

A luz disso, o direito à memória se estabelece como pauta primordial das mulheres, e nesta relação começa a constituição de uma subjetividade política e social, optando por táticas e estratégias de conscientização por meio de atividades coletivas, proporcionando o maior empoderamento do movimento. Da mesma forma que a memória e a cultura nos modelam, ela também é modelada por nós, sendo preciso um reconhecimento do valor dessa memória pelo grupo.

Em consequência dessa relação de disputa de poder, durante muito tempo as realizações femininas e a memória permaneceram em silêncio, pois, pensando politicamente, não interessava essa história ser contada (PERROT, 2012, p. 114). 0 uso da memória passa a ser um instrumento de controle, servindo de controle para a construção de uma história que limita os comportamentos dos sujeitos envolvidos, 
delimitando à mulher apenas o espaço privado para criação dos filhos e cuidado do lar, isto é, um papel de invisibilidade em relação ao homem, sempre destacado no espaço público.

\subsection{Segunda Onda}

Nas décadas entre 60 e 70, grandes revoluções aconteceram no cenário mundial: manifestações estudantis, movimentos de resistência contra a Ditadura Militar, movimento hippie e manifestações contra a guerra do Vietnã.

“A segunda onda do feminismo na América Latina nasceu nos anos 1970, em meio ao autoritarismo e à repressão dos regimes militares dominantes e das falsas democracias claramente autoritárias." (UNESCO, 2009).

Em meados dos anos 50 até meados dos anos 90, iniciam estudos centrados na origem da condição da mulher, apresentando questionamentos sobre o porquê de as mulheres serem consideradas em situação inferior a dos homens. Nesse período também começou a se construir uma base teórica sobre a opressão contra a mulher, justificada pela condição biológica e função reprodutiva.

Ao lembrar-se da estrutura patriarcal que a sociedade se constitui ao longo dos anos, o coletivo feminista se articula, unindo as experiências individuais e coletivas e questionando a situação de várias experiências de mulheres espalhadas no mundo. Hallbwacks (2013) diz que o indivíduo que lembra está inserido na sociedade na qual sempre possui um ou mais de um grupo de referência. Por isso, a memória é sempre construída em grupo, e "cada memória individual é um ponto de vista sobre a memória coletiva."

Entendem-se as lembranças como resultado de um processo coletivo, ou seja, estão inseridas em um contexto social específico, como afirma (HALBWACHS, 2013, p. 30): “lembranças permanecem coletivas e nos são lembradas por outros, ainda que trate de eventos em que somente nós estivemos envolvidos e objetos que somente nós vimos. Isso acontece porque jamais estamos sós". As mulheres ativistas que participaram da chamada segunda onda enxergavam as relações entre desigualdades culturais e políticas. Através da memória, encorajavam os sujeitos a refletirem sobre suas histórias e sobre os aspectos de suas vidas pessoais, relacionando ao poder - estrutura de poder sexista. 
Assmann (2011) indica dois modos de recordação: memória funcional e memória cumulativa. A memória funcional é responsável por assegurar a identidade do grupo, ou seja, é seletiva e remete a um grupo, indivíduo, estabelecendo uma conexão entre passado e futuro. A memória cumulativa é caracterizada por ser histórica, e por isso não depende de um sujeito específico, não é seletiva, não há critérios, tudo é importante. Com isso, Assmann (2011) compara a memória funcional à memória coletiva, e a memória cumulativa à memória histórica, a qual separa o presente, passado e o futuro, sendo a primeira habitada, e a segunda inabitada.

A memória habitada é possível alterar e ser utilizada de diversas formas. Destacase a legitimação e a deslegitimação, processo em que existe a alteração da memória, confirmando ou anulando, de acordo com propósitos políticos. Já a memória cumulativa funciona como reservatório para armazenamento de memórias funcionais, portanto não é natural, é necessário o apoio de instituições para preservá-las. Por fim, a autora afirma que "a dimensão memorial e a dimensão científica da historiografia não se excluem, pois se liga uma à outra, de maneira complexa" (ASSMANN, 2011, p. 158), sugerindo que se utilizem as duas formas para reorientar o projeto de escrita da história.

É importante, neste período de busca por uma política de igualdade de direitos, fundamentada no reconhecimento entre equidade entre os gêneros, a utilização da memória, pois "a memória se orienta para o passado e avança o passado adentro por entre o véu do esquecimento. Ela segue os rastros soterrados e esquecidos, e reconstrói provas significativas para a atualidade." (ASSMANN, p. 53. 2011).

Prova disto são expressões e slogans que se tornaram bastantes conhecidos nessa segunda onda, por exemplo, o slogan "O pessoal é político", idealizado pela feminista e autora Carol Hanish. Ela problematiza a desigualdade de união com problemas culturais e políticos, incentivando as mulheres a terem sua liberdade política para combater as estruturas sexistas de poder. Outro exemplo foi a "Liberação das mulheres" com os protestos e queima de sutiãs, com participação de cerca de quatrocentas ativistas do WLM (Women's Liberation Movement), em 1968, durante a realização do concurso de Miss América.

A crítica feminista durante esse período é o principal movimento a influenciar a história das mulheres e o amadurecimento das pautas e debates sobre a afirmação da igualdade entre os sexos, em oposição à visão parcial da história. Segundo Joan Scott: "as feministas começaram a utilizar a palavra "gênero" mais seriamente, no sentido mais 
literal, como uma maneira de referir-se à organização social da relação entre os sexos." (SCOTT,1989). Uma das estratégias foi a utilização da palavra gênero como forma de suprimir os termos mulher, mulheres e estabelecer uma nomenclatura de relação entre os sexos, de forma que não fossem acusadas de reconstruir uma história parcial.

A segunda onda é caracterizada, portanto, no avanço de percepção e análise do movimento de forma holística, incorporando em suas pautas diversas posições, denunciando a estrutura de patriarcado exercido como poder político através da dominação masculina e subversão das mulheres, além do âmbito privado, invadindo todos os espaços da sociedade (SAFFIOTI, 2004).

Fazendo crítica ao caráter burguês-liberal da primeira onda, o próprio movimento acrescenta reinvindicações acerca de classe e raça, relações de poder e transversalidade de opressões estruturais, transcendo as questões de gênero.

Destacam-se nesse período as primeiras discussões e problematizações sobre a diferença entre gênero, sexo e orientação sexual, denunciando o errado das naturalizações de papéis sociais impostos a homens e mulheres.

\subsection{Terceira Onda do Feminismo}

Como citado, na segunda onda do feminismo, uma das principais preocupações era o fim da discriminação e desigualdade entre os sexos. Como forma de responder as supostas falhas e preencher lacunas das ondas anteriores, a terceira onda, iniciada em meados da década de 80 e 90, objetivava ressignificar as definições e evitar estereótipos essencialistas acerca da mulher.

\footnotetext{
Violência, sexualidade, direito ao trabalho, igualdade no casamento, direito à terra, direito à saúde maternoinfantil, luta contra o racismo, orientações sexuais. Esses grupos organizavamse, algumas vezes, muito próximos dos movimentos populares de mulheres, que estavam nos bairros pobres e favelas, lutando por educação, saneamento, habi tação e saúde, fortemente influenciados pelas Comunidades Eclesiais de Base da Igreja Católica. (PINTO, 2010, p. 17).
}

Abordam temas sobre micropolítica e questões relativas a aspectos culturais, sociais, políticos e de cor, sobretudo o movimento feminista intersecional. Entre as principais discussões, existe a defesa da participação da mulher negra na sociedade.

Buscaram, então, mudar os modelos como a mídia e a linguagem retratavam e definiam as mulheres. 
o próprio questionamento do padrão branco de classe média-alta das feministas, mulheres negras começaram a se destacar no movimento e negociar seus espaços para revelar as diferenças vividas por mulheres com diferentes condições sociais e étnicas. (FARIA, 1997, p. 23).

O objetivo passa a ser então o reconhecimento de diversas identidades femininas e olhar crítico sobre as estratégias e organização das pautas feministas, entendendo as diferenças significativas sobre o sexo.

Fica evidente a importância de aprender sobre a vida e luta de mulheres antepassadas, como forma de legitimação e reconhecimento da estrutura patriarcal na qual estamos inseridos, valorizando a memória como instrumento no avanço da conquista de direitos. Majoritariamente, a produção histórica foi feita por homens, a partir de experiências e pontos de vista vividos por eles.

Mas, [para Foucault] a história é um jogo de forças, sem fio condutor, sem a trama de um sujeito transcendental a percorrê-la inteiramente, tornando-a inteligível, destrinçando seu sentido, buscando suas leis progressivas e evolutivas. A história não tem por detrás de si fios causais, não é a busca da origem e nem de um fim remoto. No lugar do retorno a um começo feliz, a temporalidade anônima, dispersa, sem volta. Cada trama histórica desenha uma disposição na ordem do saber, não há um sujeito soberano acima dessas disposições. Ele é tramado por elas. (...) não há um sujeito supra-histórico e sim posições possíveis de subjetividades constituídas, diferentes, porém nunca indiferentes (ARAÚJO, 2008, p. 99-100).

Implica-se, com o entendimento de história por Focault, o rompimento de uma percepção de história linear, casual e diacrônica, com base em convicção de origem e fim, a partir de rupturas e descontinuidades.

Benjamim (1994, p. 231), em seu texto sobre o conceito de história, apresenta a necessidade de narrar a experiência e afirma que o historicismo "culmina legitimamente na história universal", cujo "procedimento é aditivo". Isto é, o historicismo privilegiaria a "história dos vencedores" e acabaria apagando a memória dos excluídos, ou seja, dos esquecidos pela memória oficial. Esse papel relegado ao público feminino de insignificância foi responsável para que se entendam as razões das faltas de fontes históricas sobre sua existência concreta e sua história singular (PERROT, 2012, p. 22). Percebe-se a necessidade de construir uma história e uma memória capazes de atender as necessidades e as vivências das mulheres em sua constituição de valor, diferentemente dos papéis estereotipados. 
Assmann (2011) aponta que não há ingenuidade no rememorar. Sempre existem interesses políticos e sociais que envolvem as questões de compartilhamento, guarda e preservação, que vão além das questões práticas e tecnológicas.

Prova disto é a crescente centralização de poder pela Igreja e Estados nos "processos de coleta, armazenamento, recuperação, uso e supressão de diferentes tipos de informação" (BURKE, 2003, p. 110). Havia uma censura aos livros como forma de evitar a leitura de determinadas obras. A partir do século $\mathrm{XV}$, ao lado do registro do "tempo da igreja" e do "tempo dos negociantes", surge o "tempo dos arquivistas, cronistas e historiadores". A invenção da imprensa ajudou no desenvolvimento desta nova memória desvinculada da igreja.

Por isso, além de construir uma nova consciência, é necessário reconhecer e entender o contexto histórico, os silenciamentos, as vivências e conquistas de mulheres de décadas anteriores. Não basta reconstituir pedaço por pedaço a imagem de um acontecimento passado para obter uma lembrança. É preciso que esta reconstituição funcione a partir de dados ou de noções comuns que estejam em nosso espírito e também no dos outros, porque elas estão sempre passando destes para aqueles e viceversa, o que será possível se somente tiverem feito e continuarem fazendo parte de uma mesma sociedade, de um mesmo grupo (HALBWACHS, 2013, p. 39).

É fundamental que as lembranças sejam reconstruídas e reconhecidas pelas mulheres à sociedade, em especial o grupo feminista, através do compartilhamento de informações e lembranças para o fortalecimento do grupo social.

\subsection{Quarta Onda do Feminsmo}

Apesar de não haver consenso entre os estudiosos, parte da academia já afirma existir uma quarta onda do feminismo. Tais lutas são engendradas contemporaneamente pelos chamados coletivos, organizações fluidas, discursivamente distantes da política parlamentar e das organizações tradicionais (PEREZ; SOUZA, 2017).

Atualmente, os debates em torno das questões femininas estão cada vez mais fortes, permitindo a reflexão sobre as experiências sociais e pessoais dos sujeitos masculinos e femininos, caracterizada principalmente pela possibilidade do uso das redes sociais e tecnologias da informação e comunicação (TIC's). As feministas 
encontram um espaço para produzir, disseminar informação para mulheres em todo o mundo, sem barreiras geográficas e com facilidade de conexão.

Dessa forma, as questões feministas ocupam espaço na academia, na política e apresentam pautas de discussões mundiais, interferindo e questionando os sistemas democráticos, políticos e morais, levantando novas propostas e dando continuidade às conquistas das femininas das décadas anteriores.

As principais palavras dessa nova onda são "liberdade" e "igualdade". Essa liberdade, de acordo com Arendt (1979, p. 192), é dimensão da política. "O campo em que a liberdade sempre foi conhecida, não como problema, mas como fato da vida cotidiana, é o âmbito da política". Portanto, requer um espaço politicamente organizado, demonstrando "algo tangível em palavras que podemos escutar, em feitos que podem ser vistos e em eventos que podem ser comentandos, relembrados e transformados em estórias antes de serem incorporados, por fim, ao grande livro da história humana" (ARENDT, 1979, p. 201).

A liberdade se manifesta de forma concreta e tangível, revelada através da ação e do discurso de "criar seu próprio espaço concreto onde possa, por assim dizer, sair do esconderijo e fazer sua aparição" (ARENDT, 1979, p. 218). Porém, atualmente, há pouca representatividade feminina no cenário político, muita dificuldade para ocupação em cargos de poder, pouco espaço de fala e tomada de decisão. Isso se dá devido à exclusão das mulheres na política e na história que reverbera até hoje.

Por vários lados, as feministas passavam a feminizar-se valorizando a linguagem feminina, os atributos e os temas femininos, o que significava mais do que um simples retorno aos seus valores próprios, um alargamento do campo conceitual, através do qual teciam suas críticas à sociedade patriarcal capitalista, revelando suas armadilhas e limitações. Mais do que nunca, passaram a pensar em si mesmas sob uma ótica própria, dando visibilidade ao que antes fora escondido e recusado, o que inevitavelmente levou a uma radicalização da potencialidade transformadora da cultura feminista em contato com o mundo masculino. Tratava-se então, não mais de recusar o universo feminino, mas de incorporá-lo renovadoramente na esfera pública, o que se traduziu ainda por forçar um alargamento e uma democratização desse mesmo espaço. (Os feminismos no Brasil: dos "anos de chumbo" à era global (RAGO, 2003, p. 6).

A disputa pela memória e a luta por visibilidade são urgentes no momento atual da nossa sociedade, principalmente no contexto brasileiro, pois, em meio a onda conversadora que se destaca, estamos vivendo uma tentativa de apagamento da memória da resistência política e da leitura crítica da história. Como observa Assmann (2011), é fundamental, nesse contexto, saber o que será armazenado e o que será 
descartado. Anteriormente, até mesmo o lixo do passado era fonte de informação cultural sobre os hábitos de um povo, porém, na era das mídias digitais, a fronteira entre o que se deve lembrar e o que deve ficar esquecido é cada vez mais tênue. Nesse momento, é necessário retomar a história como pauta prioritária e utilizar a memória como objeto de disputa, pois evidencia experiências sociais diferentes por partes dos atores envolvidos e apresenta manifestações de cada grupo.

Os elementos que constituem a memória coletiva permitem que os fenômenos históricos em que as mulheres vivenciaram, de maneira individual ou coletivamente, construam uma narrativa histórica em que as feministas apresentaram novas práticas políticas e novas visões de sociedade na qual a mulher é sujeito.

\section{CONSIDERAÇÕES FINAIS}

Ao se revisar a historiografia dos movimentos feministas, podem-se perceber as principais características e algumas distinções em relação à periodização por ondas. É notório, também, o papel de esquecimento e subordinação da figura feminina em relação à figura masculina ao longo dos anos.

Por isso é tão importante entender as relações de poder e o uso da memória por toda a sociedade, para que possa servir como forma de liberdade e não de domínio de um grupo específico, valorizando dessa forma a democratização da memória.

Com mais liberdade, as mulheres descobrem a sua história e o seu papel além da procriação e afazeres domésticos a que sempre estiveram condicionadas, modificando a visão e a configuração da sociedade. Consequentemente, buscando a efetivação do seu papel a partir de registros, obras de arte e ocupação, aliadas a transformações que ocorreram no âmbito político e econômico em que o poder político estava estruturado.

Apesar de ainda não alcançarmos uma sociedade justa e igualitária, com o fim da hierarquização dos sexos, a inserção da memória ocupou um novo âmbito, possibilitou que vozes femininas nãos fossem silenciadas, sendo possível ouvir com mais frequência sobre suas participações na ciência, na história, na mídia e na participação política.

Exemplo disso é o Dia Internacional da Mulher, que se tornou um dos grandes símbolos da luta do movimento feminista, proposto por Clara Zetkin, no II Congresso Internacional das Mulheres Socialistas, em Copenhagen, em 1910 (BLAY, 2001, p. 602), comemorado até os dias de hoje em quase todos os países. Esse dia ainda é momento de 
luta e organizações de protestos, fóruns, eventos feministas contra a discriminação de sexo, e momento de propostas de reinvidicações, consolidando uma coordenação de mulheres e laços de solidariedade, oportunidade para o encontro e fortalecimento das mulheres, favorecendo para que a memória feminina não seja silenciada. (SOARES, 1994, p. 14).

Explorando essas transformações ocorridas ao longo da história, constatam-se as mudanças também no uso da memória ocorridas na contemporaneidade, e as influências exercidas sobre o jogo de poder e o convívio social. A memória tem função social nos grupos principalmente minoritários, pois sensibiliza sobre a questão do passado, da formação e construção de uma identidade coletiva.

Discutir sobre memória e movimentos sociais, sobretudo o feminista, permite ampliar a visão de pertencimento entre os sujeitos, na medida em que está inserido em um contexto social. Dessa forma, é possível valorizar fenômenos e a construção de conhecimento que esclarece e enriquece novas formas de enxergar e refletir sobre a realidade.

O desafio de estudos sobre memórias concentra-se em apresentar as experiências muitas vezes silenciadas e suprimidas de sujeitos, em geral, marginalizados da sociedade, para que possam se reencontrar com a dimensão histórica, a partir do discurso não hegemônico, com participações coletivas, abrindo oportunidades para constituição de espaços públicos diferentes, a partir de espaços de memória e de experiências vividas e partilhadas. Isto a fim de não somente "registrar fatos, à maneira da historiografia oficial, mas de contribuir ativamente para que no nosso presente não ocorra o esquecimento da tragédia" (BRUNI, 2007, p. 17).

Portanto, na medida em que a memória coletiva oferece um suporte social, promovendo a participação das mulheres, novas significações do vivido, os estudos permitem também a democratização e pluralização, através da coletivização dos fatos e reconstrução da então considerada história oficial e original, carregada do discurso de história dos que detêm o poder e, por isso, são vencedores, reproduzindo a visão dos dominadores. 


\section{REFERÊNCIAS}

AGABEM, G. 0 que é contemporâneo? E outros ensaios. Chapecó: Argos, 2009.

ALVES, Branca Moreira, PITANGUY, Jacqueline. 0 que é Feminismo? São Paulo: Ed. Abril cultural; Brasiliense, 1985.

ASSMANN, Aleida. Espaços da recordação: formas e transformações da memória cultural. Campinas, SP: Editora da Unicamp, 2011.

ARENDT, Hannah. Entre o passado e o futuro. São Paulo, Perspectiva, 1979

BANDEIRA, Lourdes; MELO, Hildete Pereira. Tempos e memórias do feminismo no Brasil. Brasília: Secretaria de Políticas para as Mulheres, 2010. Disponível em: http://www.scielo.br/scielo.php?script=sci_ nlinks\&pid=S010271822015000200256000 03\&lng=en Acesso em: 10 jan. 2016.

BRUNI, José Carlos. 0 presente: ontem e hoje. Interações: Cultura e Comunidade. 2006: 55-65. Disponível em: https://www.redalyc.org/pdf/3130/313027 308004.pdf. Acesso em: 05 de out. 2019.

BURKE, Peter. Uma história social do conhecimento: de Gutemberg a Diderot. Rio de Janeiro: Jorge Zahar, 2003. 241p.

FRANCHINI, B. S. O que são as ondas do feminismo? Revista QG Feminista, 2017. Disponível em:

https://medium.com/qg-feminista/o-que-

s\%C3\%A3o-as-ondas-do-

feminismoeeed092dae3a. Acesso em: 26. jul 2019.

FOUCAUlT, M. Vigiar e Punir. ed. Petrópolis: Vozes, 1987.

FOUCAULT, Michel. Soberania e disciplina. In: Microfísica do poder. Rio de Janeiro: Edições Graal, 1979, p. 182.

HALBWACHS, Maurice. A memória coletiva. Tradução de Beatriz Sidou. 2. ed. São Paulo: Centauro, 2013.
PERROT, Michelle. Minha história das mulheres. 2. ed. São Paulo: Contexto, 2012.

PINTO, Célia Regina Jardim. Feminismo, história e poder. Rev. Social. Polít, Curitiba, v. 18 , n. 36 , p. 15-23, jun. 2010. Disponível em:

http://www.scielo.br/pdf/rsocp/v18n36/03 . pdf Acesso em 26. Jul. 2019.

RAGO, Margareth. Os feminismos no Brasil: dos 'anos de chumbo' à era global. Revista Estudos Feministas, n. 3, jan./jul. 2003. Disponível em: http://www.unb.br/ih/his/gefem/labrys3/ web/bras/marga1.htm. Acesso em: 31 de jul. 2019.

ROUSSO, Henry. A Memória não é mais o que era. In: AMADO, Janaina: FERREIRA. Marieta de Moraes (ORG). Usos e abusos da História Oral. Rio de Janeiro, Editora FGV, 2001.

SAFFIOTI, Heleieth B. Feminismos e seus frutos no Brasil. In: SADER, Emir (Org.). Movimentos sociais na transição democrática. São Paulo: Cortez, 1986.

LARAIA, R. de B. Cultura um conceito antropológico. 14. ed. Rio de Janeiro: Zahar, 2001.

LE GOFF, Jacques. História e memória. Campinas - SP Editora da Unicamp, 1990.

SOARES, Vera. Movimento feminista paradigmas e desafios. Estudos Feministas. Ano 2. Florianópolis, 1994.

SOLEE, Kristen. 6 Things to Know About 4th Wave Feminism, 30/10/2015. Disponível em: https://www.bustle.com/articles/119524-6things-to-know-about-4th-wave-feminism. Acesso em 14 set. 2018.

OLIVEIRA, Laís Paula Rodrigues de, CASSAB, Latif Antonia. 0 movimento feminista: 
algumas considerações bibliográficas.

Simpósio Gênero e Políticas Públicas, 3, 2014, Londrina- PR. Anais do III Simpósio Gênero e Políticas Públicas, 2014. p. 13271334.
UNESCO. Olhares feministas. Hildete Pereira de Melo, Adriana Piscitelli, Sonia Weider Maluf, Vera Lúcia Puga (organizadoras). Brasília: Ministério da Educação: Unesco, 2009. 